\title{
Tanzania, United Republic of
}

National Cancer Institute

\section{Source}

National Cancer Institute. Tanzania, United Republic of. NCI Thesaurus. Code C17185.

A country in eastern Africa, bordering the Indian Ocean, between Kenya and Mozambique. 